Dragan Pamučar ${ }^{1}$, Nikola Knežević ${ }^{2}$, Dragana Macura ${ }^{2}$, Boban Đorović ${ }^{3}$ ${ }^{1}$ University of Defence in Belgrade, Military Academy; Serbia

${ }^{2}$ University of Belgrade, Faculty of Transport and Traffic Engineering, Serbia ${ }^{3}$ University of Defence in Belgrade, Military Academy; Serbia

\title{
A Fuzzy Model for Organizational Structure Design with Human Resource Allocation
}

DOI: 10.7595/management.fon.2019.0005

Abstract:

Research Question: The paper explores the problem of defining the number of required employees and their skills, as well as optimizing the work time. Motivation: Motivation for this paper arises from the fact that an organizational structure of business system has to be conceived and proportioned so as to justify the main company jobs and goals. Almost every job set for the management must be performed properly and reliably in changeable environmental conditions. In order to maintain the efficiency of complex business systems with dynamic and stochastic changeable and unchangeable variables, it is essential that the organizational structure be flexible and constantly adjusted. Idea: The idea of the paper was to develop a model for human resource allocation (HRA) in fuzzy environment. Data: The model is tested in realistic industrial environment - the example of the logistics administrative bodies in the Petroleum Industry of Serbia. Tools: To solve the problem, the following approaches are used: Fuzzy logic, Neural network and Simulated annealing. The model for HRA is based on an adaptive neuro-fuzzy inference system (ANFIS) and fuzzy mathematical model (FMM) for treating uncertainty. ANFIS-FMM model enables the human resource strategy development based on the optimisation of the employees' work time. In this ANFIS-FMM model the input variables are described using fuzzy sets represented by Gaussian functions. Using expert reasoning, an unique knowledge base is formed which enables the human resource strategy development based on the optimisation of the employees' work time. Findings: Based on authors' knowledge there is a lack of the fuzzy logic applications, adaptive neuro-fuzzy models, linear and dynamic programming, as well as heuristic and metaheuristic models related to HRA. In most of the papers, the classical methods of strategic management have been used for HRA. Contribution: In this paper the model for HRA is developed based on adaptive neuro-fuzzy technique application and FMM. The model has four main advantages over other HRA methods: the system possesses adaptability, the model is efficient in conditions of uncertainty, the neuro-fuzzy based HRA model allows dynamic decision making in HRA management through the implementation of a computer-based system, it can be IT-supported tool.

Keywords: organizational structure design, resource allocation, simulated annealing, neuro-fuzzy, fuzzy logic.

JEL classification: C61, C67, L1, L16

\section{Introduction}

Due to dynamical changing of a business environment and social changes throughout the world, human resources become a very significant resource for business and company development (Thite, Wilkinson \& Shah, 2012). Along the changes in the business environment, there are also new requirements related to human resource management activities. Companies around the world successfully respond to changes in a business environment, i.e., they are flexible toward changes thanks to employees' knowledge, skills and creativity. Companies are able to proactively respond or effectively adapt to changes in an environment thanks to employees, knowledge, skills and competences (OGC, 2011). Human resources with their own knowledge, skills and competences become an important backbone for building the company's competitiveness (Boxall \& Purcell, 2008). Therefore human resource management (HRM) has a crucial importance in the business efficiency of a company. Only with proper strategic and tactical human resource allocation (HRA), can a company be successful and progressive. Managing the available human resources should be determined by the company's strategic planning of resource allocation. Adequate resource management allows for the future goals and objectives of the company to be achieved. On the other hand, 
but not less important, dynamic HRA becomes crucially important today when the business world is rapidly changing.

In this paper the model for HRA of a company, based on certain fuzzy logical production rules, is presented. The fuzzy rule base enables the management of human resource portfolio in fuzzy environment. The authors present a universal model for HRA, based on the Adaptive Neuro-Fuzzy Inference System (ANFIS) and a fuzzy mathematical model (FMM) for HRA. ANFIS-FMM model enables the human resource strategy development based on the optimisation of the employees' work time. In changeable environment, the model helps decision makers in the process of evaluation and assessment of a company employees' potential.

The analysed problem is considered as a problem of nonlinear optimization with fuzzy inputs. To solve the problem, neuro-fuzzy logic is used. The final goal of the presented model is to make an efficient HRA of a company with the optimisation of time that is required for performing certain activities. The model gives insight into existing human potential, and also it contributes to planning and improving the employees' potential depending on the projected time for performing the activity.

In the ANFIS-FMM model inputs (expertise, equipment of the workplace, motivation, and work experience) are described by fuzzy sets that are presented by Gaussian membership functions. Based on experts' opinion, the unique knowledge base has been developed that enables the optimization of the time for performing the activity. The optimized time is the input for the FMM for HRA. The output of the ANFIS-FMM model is the required time for activities by qualifications of the human resources of the company. The proposed approach allows researchers a flexible HRA in accordance with environmental changes and it provides reasonable solutions in the context of intelligence systems.

The presented model involves studying the existing organizational structure, organizational procedures and organizational means, and analyzing the data collected. Practical work-related goals are an improvement of the methodology of designing the organizational structures, which provides a higher efficiency of the business system and the selection of adequate professional staff.

This paper is designed as follows. In the next section, we introduced a literature review of organizational design. In the third part, a new ANFIS-FMM for designing organizational structure is defined. In section 4, the results of testing the model on the example of the organizational structure of the administrative bodies in the Petroleum Industry of Serbia (PIS) are presented. Finally, in the fifth section concluding remarks are given.

\section{Brief Review of Relevant Literature for Organizational Design, Strategic and Dynamic HRM}

In recent years, the methodological approaches of computational modelling and simulation are becoming increasingly popular among organizational researchers. Simulation, unlike mathematical modelling, allows researchers to reflect the natural complexity of organizational systems as given. Computational modelling facilitates studies of more complex systems to a higher degree in comparison with traditional mathematical approaches. Many authors approached organizational design as an information-process problem (Levitt et al., 1999; Galbraith, 1977). This approach relies on the assumption that information transmission methods are relevant to consider and design organizational models.

Computational and mathematical models of organizational design may be found in the papers by Carley (1995) and Carley \& Lin (1995). Kujacic \& Bojovic (2003) proposed the model for selecting the organizational structure using the fuzzy multi-criteria analysis. The developed fuzzy multi-criteria methodology takes into consideration the uncertainty and imprecision of the input data. Researchers in the field of computational organization theory use computational analysis methods to study both humans and organizations as computational entities. Human organizations can be viewed as intrinsically computational, as many of their activities involve sharing and transforming information from one form to another and also because organizational activity is often information-driven (Simon, 1976; Carley \& Gasser, 1999).

For this reason, many researchers have developed simulation-based analysis tools for organizations during the past two decades primarily based on information processing theory (Cyert \& March, 1992; Carley \& Lin, 1995). Starting with computational modelling tools such as OrgCon in the late 1980s (Burton \& Obel, 2004), VDT in the early 90's and OrgAhead in the mid-90's, researchers and practitioners have begun using computational models of organizations for analyzing the existing organizations and designing better ones. 
The Virtual Design Team (VDT) is a project of organization modelling and the simulation tool that integrates organizational and process views of strategic time-critical projects (Levitt et al., 1999). The vision behind VDT is to offer a methodology for designing an organization in the way that an engineer designs a bridge.

Khosraviani \& Levitt (2004) developed an organizational design optimization model using genetic programming. Genetic Programming is used as an evolutionary computational optimization approach, to help project managers in finding near optimal designs for their project organizations. Organizational Consultant or OrgCon is another example of a computational model that is built based on the viewpoint that an organization is an information processing entity (Cyert \& March, 1992). Other examples are: OrgAhead (Canos \& Liern, 2004), an organizational learning model designed to test different forms of organizations under a common task representation; and OrgMem (Carley, Ren \& Krackhardt, 2000), a multi-agent simulation programme that imitates the interpersonal communication, information processing and decision making processes in organizations.

Organizational design and choosing the organizational structure for a company is the problem which has been solved using different methods, considering numerous criteria, but still there is not one method suitable for all companies. Soulsby \& Clark (2007) presented the post-socialist organizational research and the postsocialist transformation of the organization theory. Kujacic \& Bojovic (2007) presented the process and relevant issues of the postal traffic organization design. Bojovic, Kujacic \& Macura (2010) applied the ANP method for the selection among alternatives of organizational structure. An interesting approach to computational organizational modelling was used by inter alia, (Hyatt \& Jones, 1997). In this paper, an object-oriented simulation environment using difference equations for organization network modlling was developed.

Both strategic and dynamic HRM are the research subjects of many international papers. Otero et al., (2009) developed a methodology for HRM considering the existing capabilities of candidates, the required levels of expertise and the priorities of the required skills for the jobs. The authors used the Best-Fit Methodology, in order to define the suitability between the set of candidates' skills and required skills for the jobs. Xu, Song \& Chen (2005) presented a potential solution for HRA under a dynamic organizational environment. Its solution is based on fuzzy logic. Canos \& Liern (2004) proposed an expert system based on fuzzy linear programming method for personnel selection and optimal staff design. To take into consideration the environmental factors and changeable market conditions, Kwak, Shi \& Jung (2003) developed a fuzzy set approach for an audit staff-planning model. Kujacic \& Bojovic (2003) proposed the model for selecting the organizational structure by using the fuzzy multi-criteria analysis. Developed fuzzy multi-criteria methodology takes into consideration the uncertainty and imprecision of input data. Kwak \& Lee (1997) considered the problem of strategic human resource management when human resources are limited. Using a goal programming the model is developed and applied to the health-care organization.

Over the years, a large number of scientists contributed to research related to HRA models and presented various empirical research (Liao \& Xu, 2015). In addition to the mentioned models, there are many others with various applied methods such as: grey and possibilistic regression models (Ong, Huang, \& Tzeng, 2015), non-outranked ant colony optimization method (Eduardo Fernandez et al., 2015), goal programming and multi criteria (Liao \& Xu, 2015; Kocadagli \& Keskin, 2016), dynamic optimization problem (Gunasekaran \& Ramaswami, 2018), data envelopment analysis and integer programming (Tavana et al., 2017) and possibility theory (Li, Guo \& Yu, 2017). Salo, Keisler \& Morton (2011) considered in detail the literature related to the portfolio decision analysis, which provided robust methodological basics for function in a complex environment, and allows for making decisions with the aim to optimize the resources allocation.

Reviewing the relevant literature that considers the organizational structure designing and HRA in strategic management it can be concluded that there is a lack of the fuzzy logic applications, adaptive neuro-fuzzy models, linear and dynamic programming, as well as heuristic and metaheuristic models. In the majority of papers, the classical methods of strategic management have been used for HRA (Eltantawy, Giunipero \& Fox, 2009; Knight, Tu \& Preston, 2014; Lukovac \& Popovic, 2018). One of the goals of this paper is to overcome this gap through the adaptive neuro-fuzzy technique application and FMM for HRA. The proposed model is of a general type, and with slight modifications of inputs, it can be applied for HRA in other fields.

In the following section of the paper, based on relevant theoretical approaches, a new model, based on fuzzy logic, is developed for the HRA of the administrative bodies. The fuzzy model is tested on the example of the organizational structure of administrative bodies of logistic support of the Petroleum Industry of Serbia in order to analyze the situation and optimize the existing organizational structure. 


\section{Proposed Model for HRA}

Determining the time required to perform certain activities is based on the systematic approach to dimensioning of organizational structures. The systematic approach involves determining the functions, duties and qualifications of the organizational structure bodies and defining the model for determining the time of performing activities. To determine the time of performing the activities, an approach to evaluating and recording the time of work in the organizational structures is used. The obtained times are largely based on experience, intuition and subjective assessment. Considering that there is a degree of uncertainty and fuzziness about the times obtained, the theory of fuzzy sets is the most suitable mathematical tool. Since in the process of data collection there is a degree of uncertainty and fuzziness of the times obtained, the times are viewed as fuzzy numbers (Badi \& Ballem, 2018). In this paper, the times required for the execution of the activities are obtained using the fuzzy-mathematical model derived on the basis of the resource allocation model (Figure 1).

The basic principles of this model are that, starting from the goals set, the complexity of business that must be done at different levels of organizational structure are defined, in order to achieve the goals set. By the development and analysis of these sets of jobs, the time required for the execution of a certain activity is determined. The procedure is carried out through the following stages:

- defining the functions of organizational structure,

- dividing functions into jobs,

- decomposing the jobs into activities, as specific activities of direct employees,

- defining required qualifications of employees and the levels at which the jobs are performed, and

- variations of determining the time for the execution of activities by qualifications of employees.

It is particularly important to decompose the jobs into partial tasks - activities, and define the employees and the time for carrying out each of these activities. In order to predict all relevant activities within a job, it is necessary to be well acquainted with the technology of their execution. For each activity, it should be defined who will or who can do it (profiles of workers), at what level and how many resources will be engaged (time, number of people, etc.). To establish the duties and activities of the organizational structure, as well as the time needed for their execution, it is possible to use the survey method, interviews, recording method and other methods.

Phase 1: Defining the time for performing specific activity for each employee

\begin{tabular}{|c|}
\hline $\begin{array}{c}\text { Determination of the functions in the } \\
\text { organizational structure }\end{array}$ \\
\hline $\begin{array}{c}\text { Decomposition of the functions on } n \text { jobs and } q \\
\text { activities }\end{array}$ \\
\hline $\begin{array}{c}\text { Defining the needed profile of executor in the } \\
\text { organizational structure } \\
\text { activities will be performed }\end{array}$ \\
\hline $\begin{array}{c}\text { Assigning the activities to executors and defining } \\
\text { the fuzzy time for performing certain activity for } \\
\text { each executor }\end{array}$ \\
\hline
\end{tabular}

Phase 2: Optimization of the times using the ANFIS



Figure 1: Model for designing the organizational structure 
Using the rules of fuzzy arithmetic, a model was developed for determining the time required for performing a certain activity or job by qualifications which are represented as triangular fuzzy numbers. In terms of the time obtained by recording, there is a large degree of uncertainty, but we assume that it will not be longer than $t_{1}$ or less than $t_{2}$. In other words, we are sure that the time of performance belongs to the closed interval $\mathrm{T}=\left[\mathrm{t}_{1}, \mathrm{t}_{2}\right]$, which is called the confidence interval (Petrovic \& Kankaras, 2018). In addition to confidence interval, triangular fuzzy number, in our case, fuzzy time, is also characterized by the degree of belief. The concept on the basis of which the fuzzy number is expressed using confidence interval and corresponding degrees of belief was proposed by Sremac et al. (2018). The fuzzy model for designing the organizational structure of the allocation of resources includes the following steps:

Phase I

Step 1: The organizational structure is analyzed on the condition that the system has $m$ functions:

$f_{1}, f_{2}, \ldots, f_{m}$

Step 2: The jobs the system has to perform are to be defined, or decomposed into $n$ jobs:

$P_{m 1}, P_{m 2}, \ldots, P_{m n}$

Step 3: Decomposition of the jobs into activities so that each job can have $q$ activities:

$a_{m n 1}, a_{m n 2}, \ldots, a_{m n q}$

Step 4: Determining $r$ levels of the system at which the activities are to be performed:

Level $_{1}$, Level $_{2}, \ldots$, Levt

Step 5: Determining the required profile of employees in the system with $s$ qualifications:

$K_{1}, K_{2}, \ldots, K_{s}$

Step 6:The activities are assigned to employees by levels and the time for performing specific activity for each employee is defined:

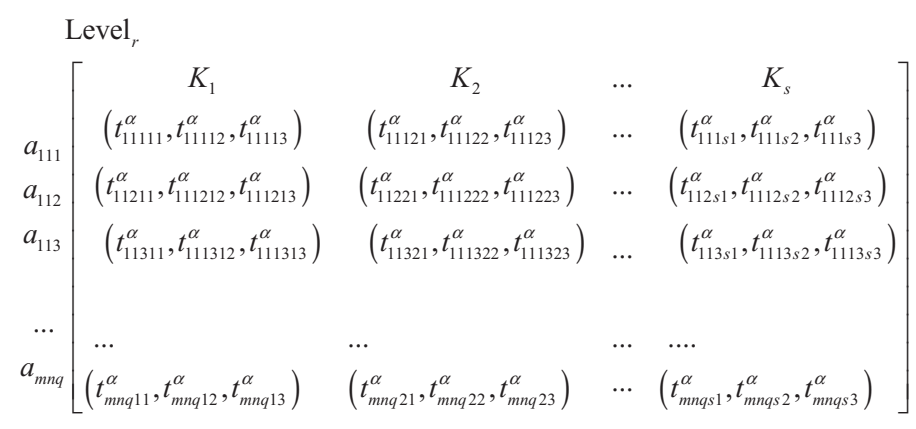

where $t_{m n q s}^{\alpha}=\left(t_{m n q s 1}^{\alpha}, t_{m n q s 2}^{\alpha}, t_{m n q s 3}^{\alpha}\right)$ is the time spent by $s$ qualification on the performance of $q$ activity of $n$ job of $m$ function.

Step 7: Summarizing the times by qualifications $\left(T_{t s}\right)$ is determined by:

$$
\sum T_{t s}^{\delta}=\sum_{i=1}^{m} \sum_{j=1}^{n} \sum_{k=1}^{q} \sum_{l=1}^{r}\left(t_{s i j k l 1}^{\delta}, t_{s i j k l 2}^{\delta}, t_{s j k l l 3}^{\delta}\right)
$$

Step 8: Defining of the distribution of confidence interval of obtained fuzzy times $\left(T_{t s}^{\delta}\right)$ for each of the observed degrees of certainty. Fuzzy times $\left(T_{t s}^{\delta}\right)$ represent the total time, in hours,

necessary for the operator of $s^{\text {th }}$ qualifications to carry out all the activities planned for her/him for the year: 


$$
\sum T_{t s}^{\delta}=\sum_{i=1}^{m} \sum_{j=1}^{n} \sum_{k=1}^{q} \sum_{l=1}^{r}\left(t_{s i j k l 1}^{\delta}, t_{s i j k l 2}^{\delta}, t_{s i j k l 3}^{\delta}\right)=\left\{\begin{array}{cl}
t_{s i j k l 1}^{\delta}=t_{s i j k l 2}^{\delta} \square, & \forall t_{s i j k l 1}^{\delta} \leq t^{\delta}<t_{s i j k l 1}^{\delta} \\
1, & \forall t_{s i j k l 2}^{\delta}=t_{s i j k l 2}^{\delta} \\
t_{s i j k l 1}^{\delta}=(2-\delta) \square t_{s i j k l 2}^{\delta}, & \forall t_{s i j k l 2}^{\delta}<t^{\delta} \leq t_{s i j k l 3}^{\delta}
\end{array}\right.
$$

Phase II

Step 9: Optimization of the summarized times $\left(T_{s i}^{\delta}\right)$ is done by the Adaptive Neuro-Fuzzy Inference System (ANFIS) modelled by means of fuzzy toolbox in the software package Matlab. The architecture and functioning of the ANFIS is described in the next section.

In the process of time optimization, for each qualification in the organizational structure, the fuzzy number is taken as confidence interval, which represents the total time the employee - executor with $n$ qualification - spends on the implementation of all the activities envisaged in hours for a year. During the practical application of the model, the interval will be proportionally adjusted depending on the obtained time necessary to be optimized.

Step 10: Determining the required number of employees with the given qualification is performed according to the expression:

$N_{k s}=\frac{T_{o}^{\delta}}{T}=\frac{\left(t_{o 1}^{\delta}, t_{o 2}^{\delta}, t_{o 3}^{\delta}\right)}{\left(t_{1}, t_{2}, t_{3}\right)}$

where $T=\left(t_{1}, t_{2}, t_{3}\right)$ triangular fuzzy number that represents the time in hours per year a person spends in the workplace, and which is determined by assessment and $N_{k s}=\left(N_{k s 1}^{\alpha}, N_{k s 2}^{\alpha}, N_{k s 3}^{\alpha}\right)$ fuzzy number that represents the required number of people with $s$ qualification for the execution of all the activities envisaged for this qualification.

Step 11: The total number of employees in one system is a fuzzy number $N=\left[N_{1}^{\alpha}, N_{2}^{\alpha}\right]$ and is determined as the sum of employees by levels:

$$
\begin{aligned}
& N=\left[N_{k 11}^{\alpha}, N_{k 12}^{\alpha}\right]+\left[N_{k 21}^{\alpha}, N_{k 22}^{\alpha}\right]+\ldots+\left[N_{k s 1}^{\alpha}, N_{k s 2}^{\alpha}\right], \\
& N=\left(N_{k 1}^{\alpha}, N_{k 2}^{\alpha}, N_{k 3}^{\alpha}\right)
\end{aligned}
$$

The concept of the described model for designing the organizational structure is shown in Figure 1.

Step 12. Defuzzification of values which represent the total number of operators $(N)$ by using the following equation:

$$
g_{\alpha, \beta}(N)=\left[\beta \square f_{\alpha}\left(N_{k 1}\right)+(1-\beta) \square f_{\alpha}\left(N_{k 3}\right)\right], 0 \leq \beta \leq 1,0 \leq \alpha \leq 1
$$

where $f_{\alpha}\left(N_{k 3}\right)=N_{k 3}-\left(N_{k 3}-N_{k 2}\right) \square \alpha$ is the right limit value of the fuzzy number confidence interval $N$; $f_{\alpha}\left(N_{k 1}\right)=\left(N_{k 2}-N_{k 1}\right)\left[\alpha+N_{k 1}\right.$ represents the left limit value (threshold) of the fuzzy number confidence interval $N$. The value $\alpha,(0 \leq \alpha \leq 1)$ represents the preference of the decision-maker, while the value $\beta$, $(0 \leq \beta \leq 1)$ represents the pessimistic index of the decision-maker. Different values of the degree of certainty, as well as changes in the allocation of functions, tasks and activities in accordance with the qualifications of the operators, give a larger number of the organizational structure alternatives. 


\subsection{Configuration of the ANFIS}

The times obtained for each qualification are optimized by applying a fuzzy logic system. For the optimization of performance time, four criteria are defined that determine the value of time more accurately and that can contribute to reducing or increasing the total time spent on performing activities by each qualification. The mentioned criteria are:

- Expertise of the employee scheduled to perform certain activity,

- Equipment in the workplace,

- The employee's desire to work (motivation), and

- Experience the employee has in performing such or similar activities.

Expertise $\left(x_{1}\right)$ for the task performance is the level of qualification which the employee has for the performance of the task. The rating is mostly based on the expertise shown in practice, primarily if the employee has already performed the same or similar activities.

Equipment in the workplace $\left(x_{2}\right)$ is the result obtained by the analysis of the state of the equipment used for the performance of tasks in the workplace in relation to the equipment that would enable a faster and better performance.

Motivation $\left(x_{3}\right)$ is the engagement demonstrated, personal commitment in the performance of all the tasks performed so far, as well as the employee's statement and interest in performing the observed activity.

Experience $\left(x_{4}\right)$ that the employee has largely depends on the number of years of service. The length of work experience that is necessary to have depends, above all, on the complexity of a given activity.

The intervals of the input and output variables of the ANFIS are shown in Table 1.

Table 1: Domain intervals for $x_{1}, x_{2}, x_{3}, x_{4}$ and $y$

\begin{tabular}{cc}
\hline Variable & Domain \\
\hline$x_{1}$ & {$[0,1]$} \\
$x_{2}$ & {$[0,1]$} \\
$x_{3}$ & {$[0,1]$} \\
$x_{4}$ & {$[0,1]$} \\
$y$ & {$\left[y_{1}, y_{2}\right]$} \\
\hline
\end{tabular}

These criteria directly influence the final time required to perform certain activities or its optimization. The criteria are, by certain logical-mathematical transformations, using the algorithm of approximate reasoning, connected and give a result expressed in hours required for the performance of activities. The structure of the model for the optimization of performance time and determining the required number of employees when designing the organizational structure is shown in Figure 2.

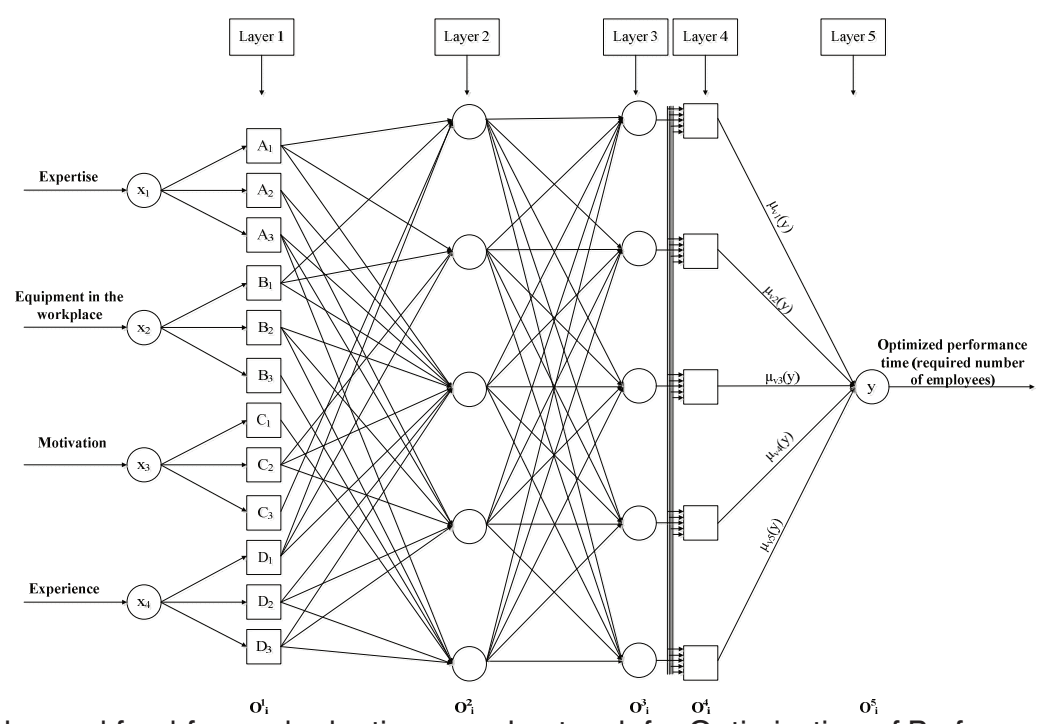

Figure 2: A five layered feed-forward adaptive neural network for Optimization of Performance Time (OPT) 
As the link between the input and the output of the fuzzy system, linguistic rules are used. The knowledge of experts on the process is expressed by a number of linguistic rules. To determine the significance of each of the criteria presented and define the rule base of the fuzzy system, a questionnaire with the information required in connection with the above criteria is sent to the addresses of 15 experts who participated in the dimensioning of organizational structures. After the replies are submitted, the data are statistically processed.

The input layer consists of 4 units: Expertise $\left(x_{1}\right)$, Equipment in the workplace $\left(x_{2}\right)$, Motivation $\left(x_{3}\right)$ and Experience $\left(x_{4}\right)$. It simply transfers inputs further via the interconnections to the hidden or first layer. All units in the input layer $\left(x_{1}, x_{2}, x_{3}\right.$ and $\left.x_{4}\right)$ are connected with the 5 units in the first layer (Pamucar \& Cirovic, 2018; Stojcic, 2018). The strengths of connections between the units in the input layer and the units in the first layer are crisp numbers equal to 1 .

The first layer consists of $4+3$ units representing the number of verbal descriptions quantified by fuzzy sets ("low", "medium", "high") for each input variable. Each unit in the first layer is an adaptive unit with its output being the membership value of the premise part (Cirovic, Pamucar \& Bozanic, 2014).

The number of units in the second layer equals the number of fuzzy rules. Each unit in this layer is a fixed unit that calculates the minimum value of the two incoming inputs (Pamucar et al., 2016). The outputs from this layer fire strengths of rules. For example, the output from the first unit in the second layer is defined as

$$
w_{1}=\min \left\{\mu_{L}\left(x_{1}\right), \mu_{H}\left(x_{2}\right), \mu_{M}\left(x_{3}\right)\right\}
$$

The third layer has five adaptive units representing the strength of the OPT ("very weak", "weak", "medium", "strong", "very strong"). Each unit in this layer calculates the intersection of a fuzzy set (consequent) with the maximum firing strength of incoming rules (Cirovic \& Pamucar, 2013). For example, the fourth unit calculates the intersection of a fuzzy set "strong preference" with the maximum firing strengths of rules $R_{5}$, $R_{6}, R_{7}: \mu_{V 4}(y)=\min \left\{w_{i}, \mu_{S P}(y)\right\}$, where $w_{i}=\max \left\{w_{5}, w_{6}, w_{7}\right\}$.

The single unit in the fourth layer is a fixed unit that computes the overall output of the ANFIS (Stojic, Sremac, Vasiljkovic, 2018):

$$
\mu_{M}(y)=\max \left\{\mu_{V 1}(y), \mu_{V 2}(y), \mu_{V 3}(y), \mu_{V 4}(y), \mu_{V 5}(y)\right\}
$$

The obtained output is then defuzzified in the single unit in the fifth layer. Selection of the final crisp value can be made in various ways (Abdulshahed and Badi, 2018). In this paper the action which is closest to the centre of gravity has been computed (Center-of-Gravity method). The output value is a real number that lies in the interval $[0,1]$ :

$$
O=\text { Overalloutput }=\sum_{i} w_{i} f_{i}=\frac{\sum_{i} w_{i} f_{i}}{\sum_{i} w_{i}}
$$

\subsection{Supervised learning}

The aim of learning is to set the membership functions of the input/output variables to some adequate functions. The neural network performances are measured as the deviation between the targeted output and the model output across all numerical examples (Mukhametzyanov \& Pamucar, 2018; Stojic et al., 2018). This discrepancy or the error measure is considered as the objective function, and heuristic simulated annealing is used to minimize it. Since the application of simulated annealing (SA) requires a large number of experiments, the training process is very long. However, the tuned FIS yields results superior to those obtained by the initial fuzzy controllers and can be used in real time (Veskovic et al., 2018).

In this paper, the objective function that has to be minimized is calculated as the sum of differences between the model output (maximum of the networks outputs) and the targeted output over all training pairs. Heuristic SA is used to minimize the objective function. A statistical training method such as SA requires the definition of an energy function (objective function) depending upon the parameters of the neural network. Whenever a new set of membership functions is generated randomly, the resulting energy is determined. If the obtained energy is improved, then a new set of membership functions is memorized, otherwise the acceptance or the rejection of the change is decided according to a given probability distribution. The possibility that a change that worsens (increases) the energy is retained implies that the algorithm would hardly be trapped in local 
energy minima. Detailed steps of the SA algorithm can be seen in Lukovac et al. (2017) and Haznedar \& Kalinli (2018).

\section{Application of the ANFIS-FMM Model}

Application of the described model will be presented through evaluation of the organization of the logistics administrative bodies in the Petroleum Industry of Serbia. The logistics administrative bodies are organized on a functional principle and carry out their tasks through the following logistic functions: supply, maintenance, transportation, general logistics and security and safety at work.

For each of the following logistic functions $k$ tasks have been identified. In the analysis of performance of the logistics administrative bodies in the Petroleum Industry of Serbia, apart from nine characteristic process functions, there is also another process function, command and control, which is typical of military organization. According to normative organizational structure, six positions-assignments have been planned within the logistics administrative bodies (LAB), Figure 3.

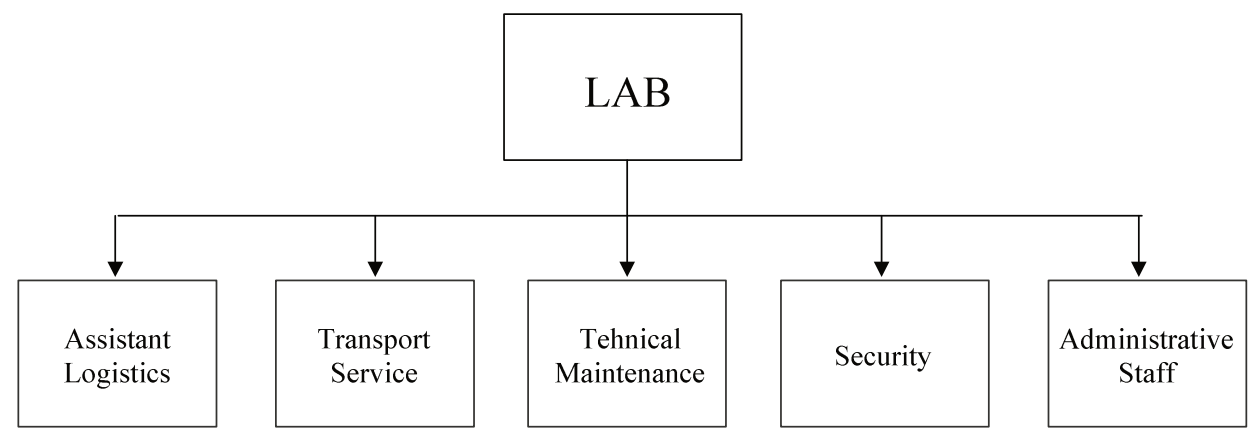

Figure 3: Existing organizational structure of the $L A B$

In designing the new organizational structure, the first step is to analyze the existing situation. It points out the need for changing and the approach in designing the organizational structure. The LAB is an organizational structure primarily intended for transport support to other units of the Petroleum Industry of Serbia. According to the defined goals of the LAB, the LAB directs available resources towards their implementation, by the accomplishment of a series of activities and tasks, which can be grouped into the appropriate functions of the LAB. Therefore, according to the tasks of the LAB, defined functions in the society and the Petroleum Industry of Serbia, as well as the existing regulations and interviews with the LAB management, the basic functions of the LAB can be described as follows: traffic and transport function, administrative function, security function, maintenance function, personnel function, control function, function of organizing, operational function and planning function.

The phase of division of the established functions of the LAB into partial assignments (tasks) is essential for determining the number of employees, because in this phase the content of features is determined. Each job consists of a number of activities that are assigned to direct employees in order to be performed. A job can have a mixed character in relation to the function affiliation. In such a case, the job affiliation is determined by the function of most of the activities that make it belong to by their character. This means that the job is obtained as a result of the analysis, or parsing each function individually. Decomposition of jobs into activities and defining the time required for their accomplishment is also important.

By the methods of interview and recording, division of command jobs by employees and levels of performance has been determined, with the times needed to perform tasks.

By the analysis assessment and in cooperation with the LAB authorities, division of activities by employees was carried out and performance times by levels defined. The times are given in hours for a period of one year. The research found that the LAB has nine functions, that there are 51 jobs, 194 activities and two performance levels (the first level - LAB manager and the second level - LAB authorities). Table 2 presents 194 activities (some of them are not presented because of space limitation) and their fuzzy times, as well as summarized values of optimized times by qualifications, obtained by ANFIS-FMM optimization. 
Table 2: Optimized fuzzy times by qualifications

\begin{tabular}{|c|c|c|c|c|c|}
\hline Activities & TrUE & ThUE & GUE & TrSE & GUE \\
\hline 1 & $(0,0,0)$ & $(0,0,0)$ & $(0,0,0)$ & $(74,82,88)$ & $(0,0,0)$ \\
\hline 2 & $(0,0,0)$ & $(0,0,0)$ & $(0,0,0)$ & $(66,75,82)$ & $(0,0,0)$ \\
\hline 3 & $(46,48,50)$ & $(0,0,0)$ & $(0,0,0)$ & $(47,52,59)$ & $(0,0,0)$ \\
\hline 4 & $(0,0,0)$ & $(0,0,0)$ & $(0,0,0)$ & $(47,52,60)$ & $(0,0,0)$ \\
\hline 5 & $(0,0,0)$ & $(0,0,0)$ & $(0,0,0)$ & $(20,26,29)$ & $(0,0,0)$ \\
\hline 6 & $(0,0,0)$ & $(0,0,0)$ & $(0,0,0)$ & $(109,115,121)$ & $(0,0,0)$ \\
\hline 7 & $(0,0,0)$ & $(0,0,0)$ & $(0,0,0)$ & $(106,113,119)$ & $(0,0,0)$ \\
\hline 8 & $(0,0,0)$ & $(0,0,0)$ & $(0,0,0)$ & $(47,52,59)$ & $(0,0,0)$ \\
\hline 9 & $(0,0,0)$ & $(0,0,0)$ & $(0,0,0)$ & $(39,42,51)$ & $(0,0,0)$ \\
\hline 10 & $(0,0,0)$ & $(0,0,0)$ & $(0,0,0)$ & $(39,42,52)$ & $(0,0,0)$ \\
\hline$\ldots$ & $\cdots$ & $\ldots$ & $\cdots$ & $\cdots$ & $\cdots$ \\
\hline 65 & $(0,0,0)$ & $(105,110,115)$ & $(0,0,0)$ & $(0,0,0)$ & $(0,0,0)$ \\
\hline 66 & $(0,0,0)$ & $(8,12,17)$ & $(0,0,0)$ & $(0,0,0)$ & $(0,0,0)$ \\
\hline 67 & $(1,2,3)$ & $(35,42,50)$ & $(0,0,0)$ & $(0,0,0)$ & $(0,0,0)$ \\
\hline 68 & $(0,0,0)$ & $(7,10,13)$ & $(0,0,0)$ & $(0,0,0)$ & $(0,0,0)$ \\
\hline 69 & $(0,0,0)$ & $(3,4,5)$ & $(0,0,0)$ & $(0,0,0)$ & $(0,0,0)$ \\
\hline 70 & $(0,0,0)$ & $(2,4,6)$ & $(0,0,0)$ & $(0,0,0)$ & $(0,0,0)$ \\
\hline 71 & $(0,0,0)$ & $(0,0,0)$ & $(0,0,0)$ & $(0,0,0)$ & $(0,0,0)$ \\
\hline$\cdots$ & $\cdots$ & $\ldots$ & $\cdots$ & $\cdots$ & $\cdots$ \\
\hline 185 & $(8,10,12)$ & $(0,0,0)$ & $(0,0,0)$ & $(3,4,5)$ & $(0.5,1,2)$ \\
\hline 186 & $(8,10,11)$ & $(0,0,0)$ & $(0,0,0)$ & $(0,0,0)$ & $(0.5,1,2)$ \\
\hline 187 & $(14,16,18)$ & $(0,0,0)$ & $(0,0,0)$ & $(6,8,10)$ & $(1,2,3)$ \\
\hline 188 & $(8,10,11)$ & $(0,0,0)$ & $(0,0,0)$ & $(8,10,12)$ & $(1,2,3)$ \\
\hline 189 & $(8,10,12)$ & $(0,0,0)$ & $(0,0,0)$ & $(0,0,0)$ & $(11,12,13)$ \\
\hline 190 & $(15,16,18)$ & $(0,0,0)$ & $(0,0,0)$ & $(11,12,15)$ & $(5,6,7)$ \\
\hline 191 & $(14,16,18)$ & $(0,0,0)$ & $(0,0,0)$ & $(29,32,39)$ & $(11,12,13)$ \\
\hline 192 & $(14,16,18)$ & $(0,0,0)$ & $(0,0,0)$ & $(6,8,10)$ & $(11,12,13)$ \\
\hline 193 & $(15,16,18)$ & $(0,0,0)$ & $(0,0,0)$ & $(0,0,0)$ & $(6,8,10)$ \\
\hline 194 & $(0,0,0)$ & $(0,0,0)$ & $(0,0,0)$ & $(0,0,0)$ & $(0,0,0)$ \\
\hline
\end{tabular}

Sum $\quad(1574,1753,1953) \quad(1259,1365,1474) \quad(1636,1752,1863) \quad(3343,3685,4002) \quad(1551,1737,1919)$ *Transportation university education (TrUE); Technical university education (ThUE); General university education (GUE); General secondary education (GSE); Transportation secondary education (TrSE)

After summarizing the times by qualifications (from Table 2), optimization of the obtained values was done using the presented fuzzy system. In Figure 4 and 5, summarized performance times are shown by qualifications.
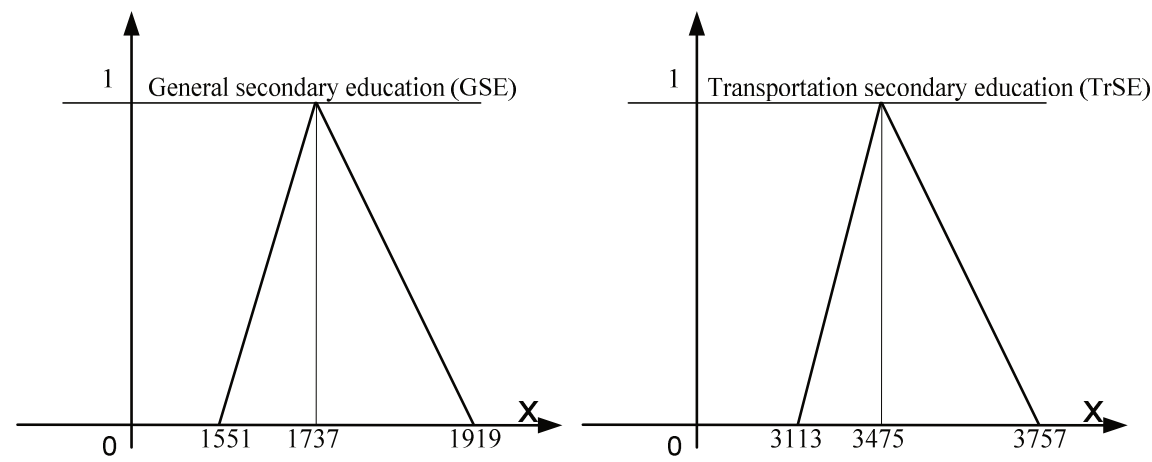

Figure 4: Summarized performance times by qualifications for the employees with secondary education 

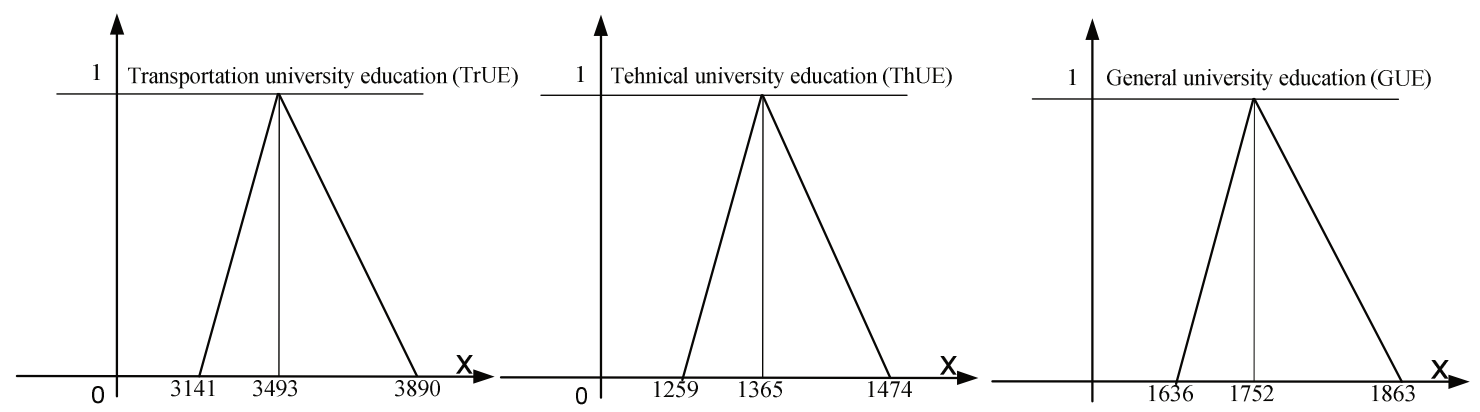

Figure 5: Summarized performance times by qualifications for the employees with university degree

The total annual working hours an employee spends on performing work activities has been determined on the basis of 40 working hours for one week. The total annual working hours for a particular employee has been determined so that the total number of weeks of the year is reduced by 10 weeks that are intended for annual leave, holidays, sick leave and other absences from the workplace. So, there are the data that an employee spends around 1680 hours annually on the performance of work activities, Figure 6.

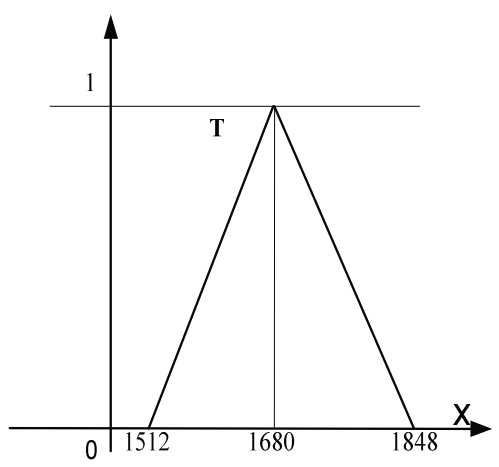

Figure 6: Total annual time one employee spends on performing work activities

The total number of employees in the LAB is determined as the sum of employees by levels. With changes in the assignment of functions, tasks and activities according to qualifications and tolerable deviations for the performance times, more variants of the number of employees are obtained.

For developing one of the variants of the organizational structure, the baseline criteria are as follows:

- that the command can perform all the tasks by its own organization,

- to ensure maximum number of employees within the LAB so that all activities are performed without the engagement of additional employees (from the car companies, logistics platoon, etc.), and

- that all the activities are professionally performed, that is, to do the proper redistribution of activities by professional qualifications of employees (that the jobs intended for those with the university degree are not given to the employees with the secondary education).

This means that the input variables in the fuzzy system will have the values of linguistic descriptors shown in Table 3.

Table 3: Values of linguistic descriptors for one of the variants of the organizational structure

\begin{tabular}{lc}
\hline Input variables & Linguistic descriptor \\
\hline Expertise & $\mathrm{VH}$ \\
Equipment in the workplace & $\mathrm{VH}$ \\
Motivation & $\mathrm{VH}$ \\
Experience & $\mathrm{VH}$ \\
\hline
\end{tabular}

In order to calculate the required number of employees by qualifications, the summarized fuzzy times by qualifications should be divided with the total annual working time (Figure 6). This relation is expressed by the equation 8 . The required number of employees with general secondary education (GSE) is defined based on the equation 8 . 
$\aleph_{G S E}=\frac{(1551,1737,1919)}{(1512,1680,1848)}=\left(\frac{1551}{1848}, \frac{1737}{1680}, \frac{1919}{1512}\right)=(0.84,1.03,1.27)$

The final number of required employees with GSE qualification is determined by equation (10), Table 4.

Table 4: Required number of employees

\begin{tabular}{cccccc}
\hline TrUE & ThUE & GUE & TrSE & GSE & Total \\
\hline 2 & 1 & 1 & 2 & 1 & 7 \\
\hline
\end{tabular}

Table 4 shows the required number of employees, and their distribution by levels, according to professional qualifications and specialties is shown in Tables 5 and 6, respectively.

Table 5: Number of employees by levels according to professional qualifications

\begin{tabular}{llc}
\hline Level & Professional qualification & Number of employees \\
LAB manager & University education & 1 \\
\cline { 2 - 3 } & University education & 3 \\
LAB authorities & Secondary education & 3 \\
\hline
\end{tabular}

Table 6: Number of Employees by levels according to specialties

\begin{tabular}{llc}
\hline Level & Specialty & Number of employees \\
\hline LAB manager & Transport & 1 \\
& Transport & 3 \\
\cline { 2 - 3 } LAB authorities & Technical & 1 \\
& General & 2 \\
\hline
\end{tabular}

The proposed mathematical models allow for the application of fuzzy multi-criteria methodology, the method of multi-criteria decision-making for the selection of appropriate organizational structure and dimensioning of organizational structure using a fuzzy model for determining the required number of employees and optimization of the time spent on performing certain functions, tasks and activities.

\section{Discussion and Conclusion}

A complex environment in which business systems operate requires planned and methodological organization design and its continuous modification and adaptation to market conditions. Convoluted operational conditions of business systems require permanent research of the model for the selection of optimal organization, and dimensioning of the organization as a dynamic model.

Starting from the basic assumptions of systematic approach, a model for resource allocation based on fuzzy logic has been developed. In setting the problem, the main considerations are in dimensioning of organizational structures with the resource allocation in hierarchically structured business systems with special emphasis on the fuzziness and uncertainty of the times required for the execution of certain functions, tasks and activities. The fuzzy logic system based on the algorithm of approximate reasoning allows the time optimization and correlates the time needed for the execution of certain functions, duties and activities with the expertise, motivation, equipment in the workplace, necessary means and experience.

This ANFIS-FMM model extends the framework of theoretical knowledge in the field of HRA. The existing problem is discussed using new methodology which creates the basis for both a theoretical and a practical upgrade. Also, the model indicates new criteria for evaluating existing human potential which have not been considered before, but are of importance for this issue. The introduction of these criteria (expertise, equipment of the workplace, motivation, and work experience) points to the need for their consideration in further analyses of this kind.

The model presented allows for the reduction of subjective impact in designing organizational solutions, improving the methodology of designing organizational structures, as dynamic changes in the society require the systems to constantly 
change and adapt, then, accelerating and facilitating work of the bodies engaged in organizational solutions of the systems and achieving better efficiency in functioning of the observed systems through the selection of adequate employees with appropriate skills and means. The proposed methodology was checked by model testing, as well as by validation of the model, on the example of defining the organizational structure of the LAB in the Petroleum Industry of Serbia. Further research should certainly be directed towards defining various alternative solutions related to organizational structure, and then using one of the known methods of multi-criteria ranking, to evaluate the variations obtained.

The model has four main advantages over other HRA methods. First, the system possesses adaptability, which is reflected through setting the base of neuro-fuzzy rules based on the characteristics of earlier human resource portfolios and the managers' heuristic experiences. The set of fuzzy rules is essential for strategic management, especially in cases when a descriptive approach is used, one that prefers intuitive, heuristic problem solving. Second, this HRA model is efficient in conditions of uncertainty. Therefore it could provide support to decision makers in the process of making the HRA strategies in uncertain environment. Third, the neuro-fuzzy based HRA model allows for dynamic decision making in HRA management through the implementation of a computer-based system. The suggested HRA model enables fast and objective assessment of the human resource portfolio in a changeable environment. Fourth, this model can be IT-supported with the formation of the appropriate database, and thus be an elegant design of the organizational structure, through the completion of changes in the assignment of functions, tasks and activities according to the qualifications of employees.

Since this is a new HRA model that has not been considered in the literature so far, further research should be dedicated to implementation of ANFIS-FMM with other traditional multi-criteria methods and their extensions with fuzzy logic. Further integration of the ANFIS-FMM approach into traditional multi-criteria models would enable the consideration of uncertainties and a decrease in subjectivism that exist in the decision making processes. Further, the research should be directed towards identifying relevant parameters that influence the optimization of the time of performing activities, which is crucial for allocating the company's resources, controlling the strategic development of human resources and preventing an adverse scenario. Therefore, the fuzzy linear and dynamic programming in collaboration with heuristic and metaheuristic methods are suitable and applicable approaches in practice. It is recommended to consider the portfolio of human resource strategies using the genetic algorithms, with defining the limitations that can be analyzed by fuzzy linear programming.

\section{REFERENCES}

[1] Abdulshahed, A.M. \& Badi, I. (2018). Prediction and control of surface roughness for end milling process using ANFIS, Operational Research in Engineering Sciences: Theory and Applications, 1(1), 1-12. DOI:10.31181/oresta1901201011a.

[2] Badi, I., \& Ballem, M. (2018). Supplier Selection using rough BWM-MAIRCA model: A case study in pharmaceutical supplying in Libya. Decision Making: Applications in Management and Engineering, 1 (2), 15-32, DOI:10.31181/dmame1802016b

[3] Bojovic, N., Kujacic, M., Macura, D. (2010). Organizational design of a post office using analytic network process; Scientific Research Essays, 5, 1194-1212

[4] Boxall, P., \& Purcell, J. (2008). Strategy and Human Resource Management, 2nd edition. Palgrave Macmillan, Basingstoke.

[5] Burton, R., \& Obel, B. (2004), Strategic organizational diagnosis and design: The dynamics of fit, 3rdedition; Boston, MA: Academic Publishers.

[6] Canos, L., \& Liern, V. (2004). Some fuzzy models for human resource management. International Journal of Technology, Policy and Management,4, 291-308. DOI:10.1504/IJTPM.2004.006613.

[7] Carley, K.M. (1995), Computational and mathematical organization theory: perspective and directions; Computational and Mathematical Organization Theory, 1, 39-56. DOI:10.1007/BF01307827.

[8] Carley, K.M., \& Gasser, L. (1999), Computational organization theory, Cambridge. MA: MIT Press.

[9] Carley, K.M., \& Lin, Z.H. (1995), Organizational designs suited to high performance under stress; IEEE Transactions on Systems Man and Cybernetics, 25, 221-230. DOI:10.1109/21.364841.

[10] Carley, K.M., Ren, Y., \& Krackhardt, D. (2000), Measuring and modeling change in c3i architectures. In Proceedings of the 2000 Command and Control Research and Technology Symposium. Naval Postgraduate School, Monterrey, CA, June, 2000.

[11] Cirovic, G., \& Pamucar, D. (2013). Decision support model for prioritizing railway level crossings for safety improvements: Application of the adaptive neuro-fuzzy system. Expert Systems with Applications, 40(6), 2208-2223. DOI:10.1016/j.eswa.2012.10.041

[12] Cirovic, G., Pamucar, D., Bozanic, D. (2014). Green logistic vehicle routing problem: Routing light delivery vehicles in urban areas using a neuro-fuzzy model. Expert Systems with Applications, 41(9), 4245-4258. DOI:10.1016/j.eswa.2014.01.005

[13] Cyert, R.M., \& March, J.G. (1992), A behavioral theory of the firm, 2nd edition, MA : Blackwell Business, Cambridge. 
[14] Eduardo Fernandez, E., Gomez, C., Rivera, G., Cruz-Reyes, L. (2015). Hybrid metaheuristic approach for handling many objectives and decisions on partial support in project portfolio optimisation, Information Sciences, 315, 102-122. DOI:10.1016/j.ins.2015.03.064

[15] Eltantawy, R.A., Giunipero, L., Fox, G.L. (2009). A strategic skill based model of supplier integration and its effect on supply management performance. Industrial Marketing Management 38, 925-936. DOI:10.1016/j.indmarman.2008.12.022

[16] Galbraith, J.R. (1977), Organization design, Addison-Wesley Publishing Company.

[17] Gunasekaran, M., \& Ramaswami, K. S. (2018). A hybrid intelligent system of ANFIS and CAPM for stock portfolio optimization. Journal of Intelligent and Fuzzy Systems, 26(1), 277-286. DOI:10.3233/IFS120736

[18] Haznedar, B., \& Kalinli, A. (2018). Training ANFIS structure using simulated annealing algorithm for dynamic systems identification. Neurocomputing, 302, 66-74. DOI:10.1016/j.neucom.2018.04.006

[19] Hyatt, A.N., \& Jones, P. (1997). Computational organizational network modeling: Strategies and an example; Computational and Mathematical Organization Theory, 3, 285-300. DOI:10.1007/BF00132313.

[20] Khosraviani, B., \& Levitt, R. (2004), Organization design optimization using genetic programming, CIFE center for integrated facility engineering, Working Paper 2004-85, Stanford University.

[21] Knight, L., Tu, J.-H., Preston, J. (2014). Integrating skills profiling and purchasing portfolio management: An opportunity for building purchasing capability. International Journal Production Economics, 147, 271-283. DOI:10.1016/j.ijpe.2013.06.013.

[22] Kocadagli, O, Keskin, R. (2015). A novel portfolio selection model based on fuzzy goal programming with different importance and priorities. Expert Systems with Applications, 42 (2015) 6898-6912. DOI:10.1016/j.eswa.2015.04.047.

[23] Kujacic, M., \& Bojovic, N. (2003), Organizational design of post corporation structure using fuzzy multicriteria decision making; Computational and Mathematical Organization Theory, 9, 5-18. DOI:10.1023/B:CMOT.0000012306.85541.8d

[24] Kujacic, M., \& Bojovic, N. (2007). Postal Traffic Organizational Design; Postal Technol. Int., 4, 92-94.

[25] Kwak, N.K., Lee, Ch. (1997), A linear goal programming model for human resource management in a health-care organization. Journal of Medical Systems, 21, 129-140. DOI:10.1023/A:1022850505219.

[26] Kwak, W., Shi, Y., Jung, K. (2003). Human resources allocation in a CPA firm: A fuzzy set approach. Journal Review of Quantitative Finance and Accounting, 20, pg. 277-290. DOI:10.1023/A:1023676529552.

[27] Levitt, R.E., Thomsen, J., Christiansen, T.R., Kunz., J.C., Jin, Y., Nass, C. (1999). Simulating project work processes and organizations: Toward a micro-contingency theory of organizational design; Management Science, 45, 1479-1495; DOI:10.1287/mnsc.45.11.1479

[28] Li, X., Guo, S., \& Yu, L. (2017). Skewness of fuzzy numbers and its applications in portfolio selection. IEEE Transactions on Fuzzy Systems. 23(6), 2135-2143. DOI:10.1109/TFUZZ.2015.2404340

[29] Liao, H., \& Xu, Z. (2015). Approaches to manage hesitant fuzzy linguistic information based on the cosine distance and similarity measures for HFLTSs and their application in qualitative DOI:10.1016/j.eswa.2015.02.017

[30] Lukovac, V., Pamucar, D., Popovic, M., Djorovic, B. (2017). Portfolio model for analyzing human resources: An approach based on neuro-fuzzy modeling and the simulated annealing algorithm, Expert Systems with Applications, 90, pp. 318-331. DOI:10.1016/j.eswa.2017.08.034.

[31] Lukovac, V., \& Popovic, M. (2018). Fuzzy Delphi approach to defining a cycle for assessing the performance of military drivers. Decision Making: Applications in Management and Engineering, 1(1), 67-81. DOI:10.31181/dmame180167l.

[32] Mukhametzyanov, I., \& Pamucar, D. (2018). A sensitivity analysis in MCDM problems: A statistical approach. Decision Making: Applications in Management and Engineering, 1(2), 51-80. DOI:10.31181/dmame1802050m.

[33] OGC (Office of Government Commerce) (2011). Management of Portfolios. The Stationery Office, Norwich, 2011.

[34] Ong, C.-S. Huang, J.-J. Tzeng, G.-H. (2015). A novel hybrid model for portfolio selection, Applied Mathematics and Computation, 169(2), 1195-1210. DOI:10.1016/j.omega.2007.06.002

[35] Otero, L.D., Centeno, G., Riuz-Torres, A., Otero, C. (2009), A systematic approach for resource DOI:10.1016/j.cie.2008.08.002.

[36] Pamucar, D., \& Cirovic, G. (2018). Vehicle route selection with an adaptive neuro fuzzy inference system in uncertainty conditions. Decision Making: Applications in Management and Engineering, 1(1), 13-37. https://doi.org/10.31181/dmame180113p.

[37] Pamucar, D., Vasin, Lj., Atanaskovic, P., Milicic, M. (2016). Planning the city logistics terminal location by applying the green p-median model and type-2 neuro-fuzzy network. Computational Intelligence and Neuroscience, 5265, 1-25, DOI:10.1155/2016/6972818. 
[38] Petrovic, I., \& Kankaras, M. (2018). DEMATEL-AHP multi-criteria decision making model for the selection and evaluation of criteria for selecting an aircraft for the protection of air traffic. Decision Making: Applications in Management and Engineering, 1(2), 93-110. DOI:10.31181/dmame1802091p.

[39] Salo, A., Keisler, J., \& Morton, A. (2011). An invitation to portfolio decision analysis. In A. Salo, J. Keisler, \& A. Morton (Eds.), Portfolio Decision Analysis: Improved methods for resource allocation, 3-27, New York: Springer.

[40] Simon, H.A. (1976), Administrative behavior; A study of decision-making processes in administrative organization, New York.

[41] Soulsby, A., \& Clark, E. (2007), Organization theory and the post-socialist transformation: Contributions to organizational knowledge, Human Relations, 60, 1419-1442. DOI:10.1177/0018726707083470.

[42] Sremac, S., Tanackov, I., Kopic, M., Radovic, D. (2018). ANFIS model for determining the economic order quantity. Decision Making: Applications in Management and Engineering, 1(2), 81-92. DOI:10.31181/dmame1802079s.

[43] Stojcic, M. (2018). Application of ANFIS model in road traffic and transportation: a literature review from 1993 to 2018. Operational Research in Engineering Sciences: Theory and Applications, 1(1), 40-61. DOI:10.31181/oresta19012010140s.

[44] Stojic, G., Sremac, S., Vasiljkovic, I. (2018). A fuzzy model for determining the justifiability of investing in a road freight vehicle fleet. Operational Research in Engineering Sciences: Theory and Applications, 1(1), 62-75. DOI:10.31181/oresta19012010162s.

[45] Tavana, M., Keramatpour, M., Santos-Arteaga, J.F., Ghorbaniane, E. (2017). A fuzzy hybrid project portfolio selection method using Data Envelopment Analysis, TOPSIS and Integer Programming. Expert Systems With Applications, 42, 8432-8444. DOI:10.1016/j.eswa.2015.06.057.

[46] Thite, M., Wilkinson, A., Shah, D. (2012). Internationalization and HRM strategies across subsidiaries in multinational corporations from emerging economies - a conceptual framework. Journal of World Business, 47, 251-258. DOI:10.1016/j.jwb.2011.04.012.

[47] Veskovic, S., Stevic, Z., Stojic, G., Vasiljevic, M., Milinkovic, S. (2018). Evaluation of the railway management model by using a new integrated model DELPHI-SWARA-MABAC. Decision Making: Applications in Management and Engineering, 1(2), 34-50. DOI:10.31181/dmame1802034v.

[48] Xu, Z., Song, B., \& Chen, L. (2005), Fuzzy logic experience model in human resource management. Lecture Notes in Computer Science, Knowledge -Based Intelligent Information and Engineering Systems, 1298-1304. DOI: 10.1007/11552451_179.

Received: 2018-06-03

Revisions requested: 2018-07-28

Revised: 2018-01-18 (3 times)

Accepted: 2019-01-31

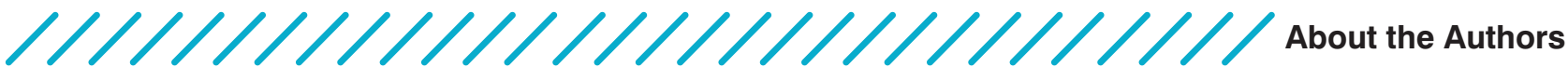

\begin{abstract}
Dragan Pamučar
University of Defence in Belgrade, Military Academy, Department of logistics, Serbia e-mail: dpamucar@gmail.com
\end{abstract}

Dragan Pamucar is an assistant professor at the University of Defence in Belgrade, Department of Logistics, Serbia. Dr. Pamucar received a PhD in Applied Mathematics with specialization of Multi-criteria modelling and soft computing techniques in logistics from the University of Defence in Belgrade, Serbia in 2013 and an MSc degree from the Faculty of Transport and Traffic Engineering in Belgrade in 2009. His research interests lie in the fields of multi-criteria decision making problems, fuzzy logic, intuitionistic fuzzy set theory, rough and neutrosophic theory. Dr. Pamucar has authored/co-authored over 50 papers published in refereed international journals including Experts Systems with Applications, Computational intelligence, Applied soft computing, Sustainability,

Symmetry, Water, Asia-Pacific Journal of Operational Research, Operational Research, Journal of Intelligent and Fuzzy Systems, Land Use Policy, Environmental impact

assessment review, Neural computing and applications, Economic computation and economic cybernetics studies and research and so on, and many more.

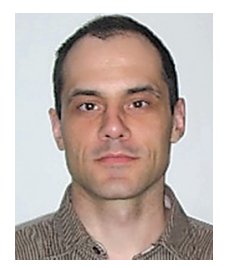




\section{Nikola Knežević \\ University of Belgrade, Faculty of Transport and Traffic Engineering, Serbia e-mail: n.knezevic@sf.bg.ac.rs}

Nikola Knežević, $\mathrm{PhD}$, is an assistant professor at the Faculty of Transport and Traffic Engineering, University of Belgrade, Serbia. His area of academic interests includes: project management, organizational design, performance management and application of quantitative methods in management. He is the author and co-author of one book and over 40 papers published in scientific journals and at scientific conferences. He was a reviewer of one book (monograph). In his previous career, he was engaged by the Government of the Republic of Serbia in the Development Strategy of postal services, and by the Government of Montenegro in the Development Strategy of postal traffic.

Dragana Macura

University of Belgrade, Faculty of Transport and Traffic Engineering, Serbia e-mail: d.macura@sf.bg.ac.rs

Dragana Macura is an associate professor at the University of Belgrade, Faculty of Transport and Traffic Engineering, Department for Railway Engineering. Her main fields of interest are: railway transport, transport project management, transport economics, railway marketing, and application of operational research methods in transport industry. Prof. Dr. Macura is the author and co-author of two monographs, and over $\mathbf{4 0}$ published scientific papers.

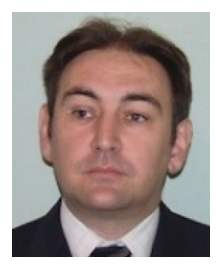

Boban Đorović

University of Defence in Belgrade, Military Academy; Serbia e-mail: boban.djorovic@mod.gov.rs

Boban D. Đorovic was born in Kragujevac in 1969. He received his BS, MS and PhD degrees from the Technical Military Academy in Belgrade. His main research interests include: Organizational design, Organization in Transport, Operations management,

Multicriteria decisions, etc. He is a full-time professor at the Military Academy in

Belgrade, teaching Organization design and Operations Research in Traffic.

Prof. Dr. Đorović has published papers in scientific journals such

as Yugoslav Journal of Operational Research, Experts Systems with Applications, Economic computation and economic cybernetics studies and research and many more. Prof. dr Đorović is also the author of several professional books, in the area of Management and Organization Science. 